\title{
Investigation into high-frequency-vibration assisted micro-blanking of pure copper foils
}

\author{
Chunju Wang ${ }^{1,2, a}$, Bin Guo ${ }^{1}$, Debin Shan ${ }^{1}$, and Yi Qin ${ }^{2}$ \\ ${ }^{1}$ School of Materials Science and Engineering, Harbin Institute of Technology, 150001 Harbin, China \\ ${ }^{2}$ Department of Design, Manufacturing \& Engineering Management, University of Strathclyde, \\ G1 1XJ Glasgow, UK
}

\begin{abstract}
The difficulties encountered during the manufacture of microparts are often associated with size effects relating to material, process and tooling. Utilizing acoustoplastic softening, achieved through a high-frequency vibration assisted micro-blanking process, was introduced to improve the surface finish in micro-blanking. A frequency of $1.0 \mathrm{kHz}$ was chosen to activate the longitudinal vibration mode of the horn tip, using a piezoelectric actuator. A square hole with dimensions of $0.5 \mathrm{~mm} \times 0.5 \mathrm{~mm}$ was made, successfully, from a commercial rolled T2 copper foil with $100 \mu \mathrm{m}$ in thickness. It was found that the maximum blanking force could be reduced by $5 \%$ through utilizing the high-frequency vibration. Proportion of the smooth, burnished area in the cut cross-section increases with an increase of the plasticity to fracture, under the high-frequency vibration, which suggests that the vibration introduced is helpful for inhibiting evolution of the crack due to its acoustoplastic softening effect. During blanking, roughness of the burnished surface could be reduced by increasing the vibration amplitude of the punch, which played a role as surface polishing. The results obtained suggest that the high-frequency vibration can be adopted in micro-blanking in order to improve quality of the microparts.
\end{abstract}

\section{Introduction}

With reference to the manufacture of micro/miniature parts for product miniaturization, microforming, which offers attractive characteristics such as high productivity, low cost and good qualities of the formed parts, provides a promising method of fabricating metallic microparts $[1,2]$. However, size effect existing during the miniaturization of parts, such as in a coining process [3], represents a significant challenge in microforming compared with the traditional forming process. To overcome some drawbacks associated with size effect, many new processes were attempted. In particular, introducing external, physical fields to assist in the forming process has been considered, and one of them being ultrasonic/high frequency vibration.

In 1955, F. Blaha and B. Langenecker found that the flow stress of materials would decrease when the ultrasonic vibration was applied [4], which was also observed in the micro upsetting [5]. This kind of

\footnotetext{
${ }^{a}$ Corresponding author: cjwang1978@hit.edu.cn
}

This is an Open Access article distributed under the terms of the Creative Commons Attribution License 4.0, which permits unrestricted use, distribution, and reproduction in any medium, provided the original work is properly cited. 


\section{MATEC Web of Conferences}

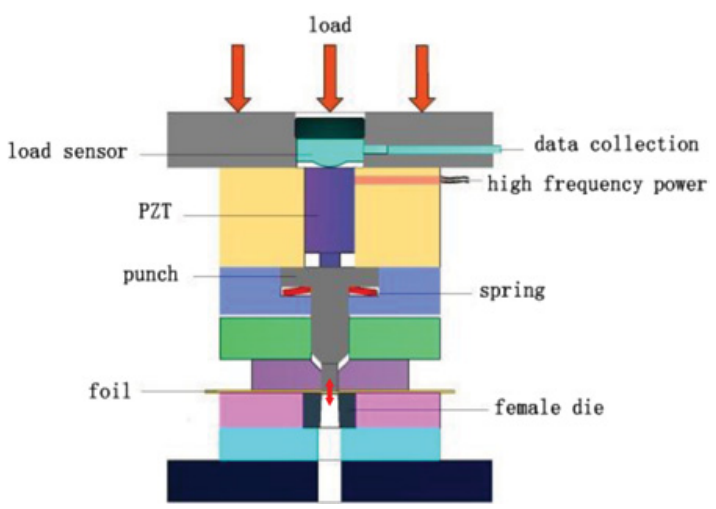

Figure 1. Schematic diagram of the device for high-frequency vibration assisted micro-blanking.

softening effect was applied in different microforming processes, e.g. decreasing the forming load about $23 \%$ in micro-extrusion [6], punch force in micro deep drawing [7], and surface roughness by $50 \%$ in micro-forging [8]. The investigations of the micro-blanking showed that the surface finish became worse for the large ratio of grain size to the single relative clearance between the punch and the female die [9]. By using the ultrasonic vibration, the surface with high burnished area was obtained in a micro punching process $[10,11]$. However, effects of high-frequency vibration on micro-blanking need to be investigated systematically.

In this investigation, a high-frequency vibration assisted micro-blanking process was carried out with a focus on the improvement of the surface finish, using acoustoplastic softening effect. The effect of vibration was investigated in details through analysing micro-blanking force, proportion of the smooth burnished surface and its surface roughness. Mechanism of the effect of vibration on the improvement of surface finish was analysed and discussed, with reference to acoustoplastic softening effect in particular.

\section{Experiment}

\subsection{High-frequency vibration assisted micro-blanking device}

Although blanking as a mature process is frequently used in the metal sheet forming, continuous research effort is still made towards ever improved quality concerning surface finish and miniaturisation. The aim of this investigation is to obtain higher proportion of the burnished surface utilizing highfrequency vibration.

To realize the high-frequency vibration assisted micro-blanking, a piezoelectric (PZT) actuator was chosen to provide a longitudinal vibration frequency of $1.0 \mathrm{kHz}$ as shown in Fig. 1. The actuator was installed in the upper part of the forming device which acts on the micro punch directly. A merit of such an arrangement is that the actuator can directly drive the micro-punch without much loss of the energy. The frequency and amplitude of the vibration were controlled by a driver named XE-500/501. The maximum frequency and amplitude achievable are $1.0 \mathrm{kHz}$ and $2.67 \mu \mathrm{m}$ respectively.

An XFC200R micro-load sensor developed by FGP was embedded into the forming device, upon the PZT actuator. Data collection system DEWETRON was used for collecting the force data. The punch force can be obtained directly at a high frequency, which is able to meet the requirement of examining vibration assisted forming with a range of high-frequencies.

With reference to the piercing of a square hole with dimensions of $0.5 \mathrm{~mm} \times 0.5 \mathrm{~mm}$, a series of punches and female dies with different clearances were designed and manufactured with tool steel SKD11. The clearances at one single side between the punch and the female die were chosen as 3\%, 


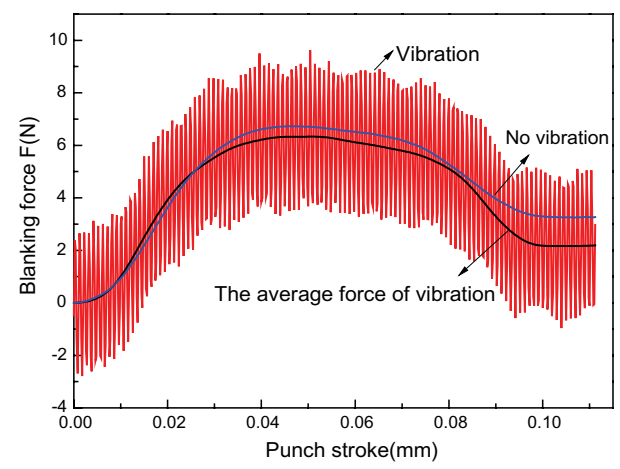

Figure 2. Curves of the blanking force- punch stroke with and without vibration.

$5 \%, 8 \%, 10 \%$ and $15 \%$ of the foil thickness, respectively. All the experiments were carried out at a room temperature, with a DT-3H micro-blanking machine developed by Seki Corporation in Japan.

\subsection{Material}

The commercial rolled T2 copper foil of $100 \mu \mathrm{m}$ in the thickness was chosen for the investigation. To eliminate the hardening induced during the production of the rolled foil, the copper foil was annealed within vacuum for one hour, at temperature of $400{ }^{\circ} \mathrm{C}$. The obtained grain size was measured to be $12 \mu \mathrm{m}$ with a metallic analysis method.

\section{Results and discussion}

\subsection{Effects of the vibration on the blanking force}

Micro-blanking experiment was performed at a punch-speed of $1.0 \mathrm{~mm} / \mathrm{min}$. With and without vibration, blanking forces were obtained, as shown in Fig. 2. Under the high frequency vibration, the curve of the banking force measured is not smooth which was due to the change of the force amplitude frequently (the cyclic curve shown in Fig. 2). Thus, it is difficult to directly compare the blanking forces with and without vibration. Therefore, average value of the force was used for comparison, when evaluating effect of the vibration. The comparison between the average force with the vibration and blanking force without vibration showed that the maximum blanking force could be reduced by $5 \%$ from that without vibration. This can be attributed to the high-frequency vibration softening on the material, which has been documented in previous investigations, comprised of stress superposition and acoustoplastic softening [11]. When the shear area is kept to be constant during blanking, the obtained blanking force decreases with the application of the high-frequency vibration.

When the amplitude of vibration was changed, the obtained maximum punch forces were almost the same. This is different from the previous results because the input power is almost kept to be constant in this investigation. When the vibration amplitude is changed by changing input voltage, the frequency of vibration is changed accordingly to keep the power as a constant for the work mechanism of the PZT used in this study. This is different from previous investigations, in which the stress reduction due to acoustic softening mainly depended on the vibration amplitude. In fact, the stress reduction by the acoustic softening effect was observed to be proportion to the square root of acoustic energy density. So, it may be concluded that the acoustic softening effect is affected mainly by the energy input. In this study, the energy input was kept as a constant, although the amplitude was changed, which lead to a similar level of the maximum blanking force observed. 


\section{MATEC Web of Conferences}

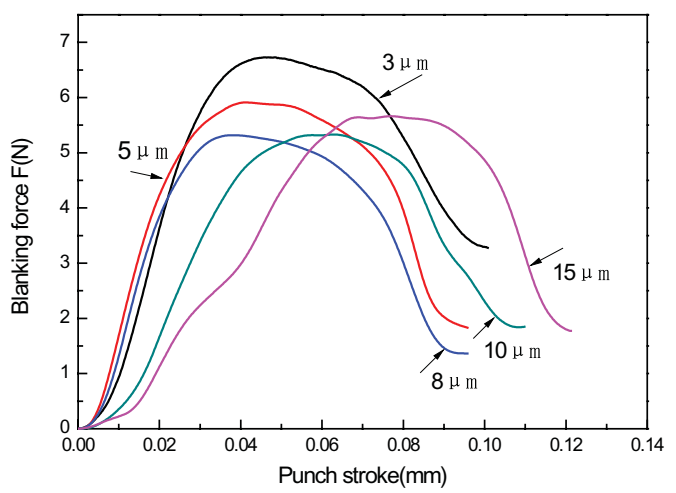

Figure 3. Curves of blanking force-punch stroke for different relative blanking clearances without vibration.

\subsection{Effect of the relative blanking clearance on the blanking force}

Using the micro punches and female dies with different relative blanking clearances from $3 \%(3 \mu \mathrm{m})$ to $15 \%(15 \mu \mathrm{m})$, micro-blanking was carried out with a copper foil with grain size of $12 \mu \mathrm{m}$. The obtained blanking force-punch stroke curves under different relative blanking clearances and without the high frequency vibration are shown in Fig. 3. It indicates that the relative blanking clearance has an obvious effect on the blanking force. Both the slope of the curve and the maximum force were changed with the changing of clearance. For the maximum blanking forces, there is a minimum point for different clearances. In this investigation, the maximum blanking force was analysed in details with a view to studying effect of the high frequency vibration. A comparison of the maximum blanking force between those with and without vibration is shown in Fig. 4. In general, the maximum blanking force decreases with increase of the relative blanking clearance, and in the end, for the clearance of $15 \%$, the maximum blanking force increases slightly. This means that a lowest point in the curve appears for the relative clearance of $8 \%$. When the high frequency vibration was applied, the maximum blanking force was reduced, and the reduction of the maximum blanking force was higher for the small clearance than that for large ones. For example, the reduction of the blanking force is $20 \%$ for a relative clearance of $3 \%$. However, there is almost no reduction for the relative clearance of $15 \%$. This may also be attributed to the acoustic softening effect on the material. For the small relative blanking clearance, severe plastic deformation occurs because there is only a small space for the dislocations in grains to move. In the vibration assisted deformation, it causes absorption of sufficient energy at dislocation sites to activate dislocations and to free them from their pinned equilibrium positions when the energy is over a critical value, which is the reason of softening and is helpful for the subgrain formation. The extent of softening and subgrain formation is dependent on the dislocation mobility, cross-slip ability and crystal structure that can affect dislocation annihilation. When the severe plastic deformation occurs, the vibration-induced enhancement of dislocation annihilation and subgrain formation is a rather universal phenomenon, and the flow stress should decrease due to reduced strain-hardening. Thus, the acoustic softening effect becomes clearer when a small relative blanking clearance is used.

\subsection{Effect of the vibration on the surface quality of cross section}

High-frequency vibration is helpful for improving surface finish in micro-blanking. To gain more insight on the surface quality of the cross section, the proportion of the burnished surface and its surface roughness were evaluated using a Laser Scanning Confocal Microscope (LSCM). The proportions of the burnished surface under different punch-velocities are shown in Fig. 5. When the punch-velocity 


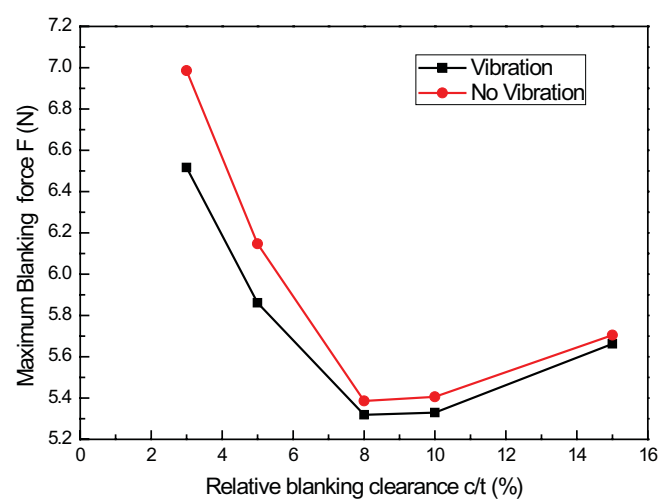

Figure 4. Effect of relative blanking clearance on the maximum blanking force.

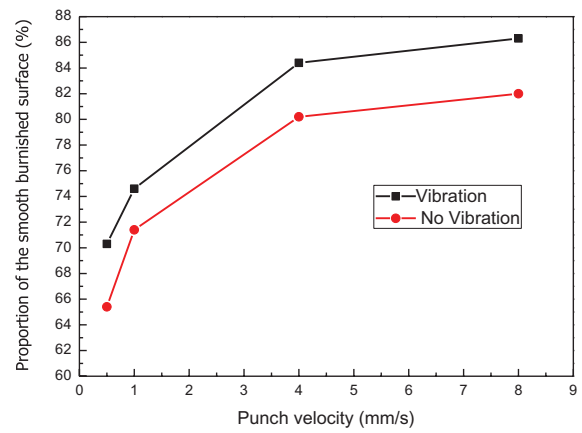

Figure 5. Proportion of the burnished surface under different punch-velocities.

of $0.5 \mathrm{~mm} / \mathrm{min}$ was applied, proportion of the smooth burnished surface increases from $65.4 \%$ for that without vibration to about $70.3 \%$ for that with vibration applied. This may be explained by considering two aspects: in the beginning of the blanking, the softening induced by the high frequency vibration improves the plastic flow of the material and postpones the shear-deformation stage in the blanking. As a result, proportion of the burnished surface increases. On the other hand, with an increase of the duration of vibration, the acoustic hardening effect may occur when the activated dislocations are more than the annihilated dislocations. When crack propagation occurs, hardening effect becomes more significant because plastic deformation takes place mainly at the crack tip. The hardening at the crack tip could inhibit the propagation of the crack.

Another important parameter is the vibration amplitude. Photograph of cross section indicates that a burnished surface becomes smoother with the increase of the vibration amplitude (Fig. 6). To quantitatively evaluate effect of the vibration amplitude, surface roughness of the burnished surface is measured using LSCM, and the results being shown in Fig. 7. It reveals that the vibration amplitude has a significant effect on the surface roughness, e.g. the surface roughness decreases from $R a 1.4 \mu \mathrm{m}$ for the vibration amplitude of $0.27 \mu \mathrm{m}$ to $R a 0.73 \mu \mathrm{m}$ for the vibration amplitude of $2.67 \mu \mathrm{m}$. The surface roughness $R a$ was reduced about $50 \%$. This result can be attributed to the polishing effect of the reciprocating motion of the punch. When the high-frequency vibration was applied on the punch, it moves up and down rapidly along the longitudinal direction during micro-blanking. At the same time, there is a lateral contact pressure between the punch and the foil, being responsible for the existence of the plastic deformation. Then, the surface roughness peaks of the burnished surface were planished 


\section{MATEC Web of Conferences}

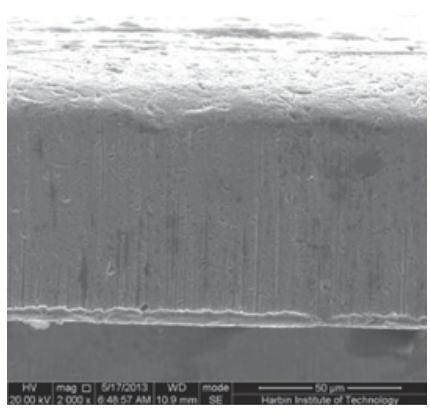

(a) $0.27 \mu \mathrm{m}$

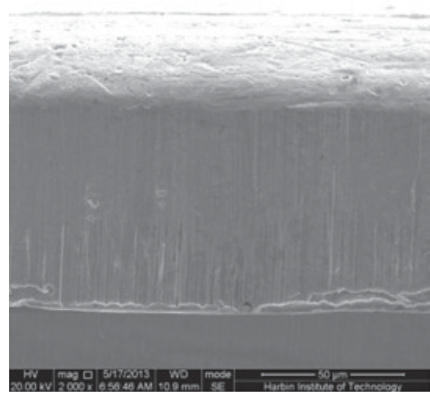

(b) $0.67 \mu \mathrm{m}$

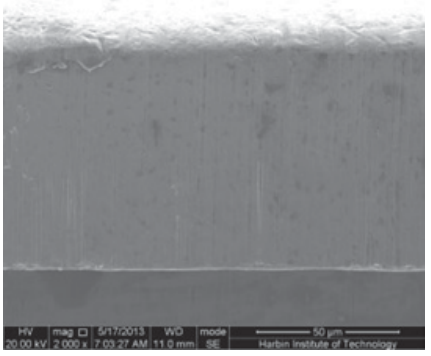

(c) $2.67 \mu \mathrm{m}$

Figure 6. Surface topography of the cross section under different amplitudes.

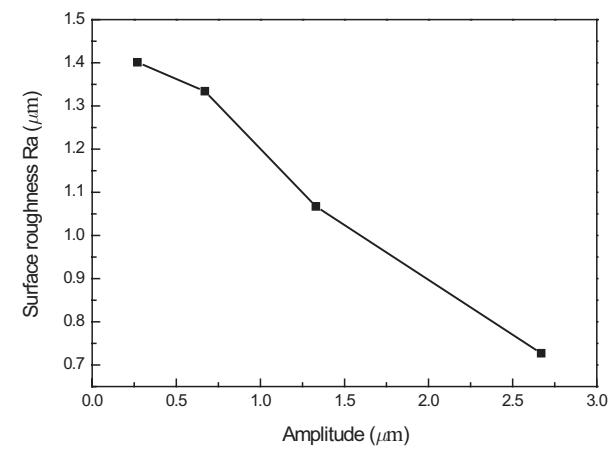

Figure 7. Effect of the amplitudes on surface roughness of the burnished surface.

by the lateral surface of the punch. The bigger is the vibration amplitude, the smoother is the burnished surface.

\section{Conclusions}

The research in high-frequency vibration assisted micro-blanking has led to the following conclusions:

(1) Due to high-frequency vibration softening, the maximum blanking force with vibration could be reduced, e.g. by $5 \%$, comparing to that without vibration.

(2) The vibration has a more influence on the blanking force, when the relative clearance is small, e.g. 3\%, the reason for which may be explained as that vibration-induced softening is clearly seen when a severe plastic deformation occurs at the narrow area under such a condition,.

(3) Proportion of the burnished surface of the cut cross-section increases from $65.4 \%$ for blanking without vibration to $70.3 \%$ for that with vibration. This may be explained as a softening effect at the beginning stage and a hardening effect at the latter stage, and both of these being helpful for inhibiting propagation of the crack in micro-blanking.

(4) Surface roughness of the burnished surface decreases from $R a 1.4 \mu \mathrm{m}$ for the vibration amplitude of $0.27 \mu \mathrm{m}$ to $R a 0.73 \mu \mathrm{m}$ for that of $2.67 \mu \mathrm{m}$, which can be attributed to a polishing effect of the reciprocating motion of the punch during micro-blanking. 


\section{ICNFT 2015}

The authors would like to acknowledge financial support from the National Science Foundation of China through a funded project (No. 51375113).

\section{References}

[1] M.W. Fu, W.L. Chen, Int. J. Adv. Manuf. Tech., 67, 2411-2437 (2013)

[2] Y. Qin, A. Brockett, Y. Ma, A. Razali, J. Zhao, C. Harrison, W. Pan, X. Dai, D. Loziak, Int. J. Adv. Manuf. Tech., 47, 821-837 (2010)

[3] C.J. Wang, D.B. Shan, J. Zhou, B. Guo, L.N. Sun, J. Mater. Process. Tech., 187-188, 256-259 (2013)

[4] F. Blaha, B. Langenecker, Die Naturwissenschaften, 42, 556 (1955)

[5] Z.H. Yao, G.Y. Kim, L. Faidley, Q.Z. Zou, D.Q. Mei, Z.C. Chen, J. Mater. Process. Tech., 212, 640-646 (2012)

[6] C. Bunget, G. Ngaile, Ultrasonics, 51, 606-616 (2011)

[7] Y.M. Huang, Y.S. Wu, J.Y. Huang, Int. J. Adv. Manuf. Technol., 71, 1455-1461 (2014)

[8] Y. Bai, M. Yang, J. Mater. Process. Tech., 213, 330-336 (2013)

[9] J. Xu, B. Guo, C.J. Wang, D.B. Shan, Int. J. Mach Tool. Manu., 60, 35-42 (2012)

[10] T. Takemasu, S. Yamasaki, H. Miura, T. Ozaki, Proceeding of the 8th ICTP, 2005

[11] A.T. Witthauer, G.Y. Kim, L.E. Faidley, Q.Z. Zou, Z. Wang, Mater. Manuf. Process., 29, 1184-1189 (2014) 